Utah State University

DigitalCommons@USU

$5-14-2019$

\title{
Validation of Digital Surface Models (DSMs) Retrieved From Unmanned Aerial Vehicle (UAV) Point Clouds Using Geometrical Information From Shadows
}

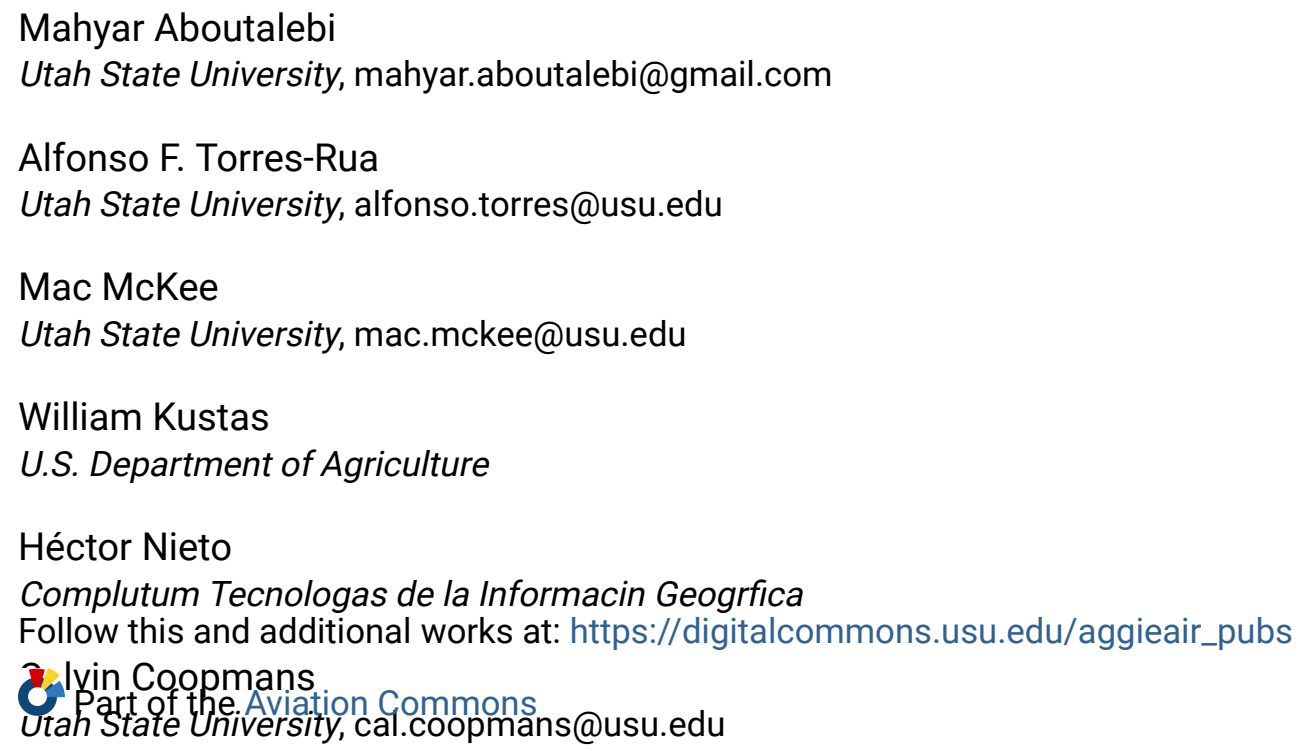

\section{Recommended Citation}

Mahyar Aboutalebi, Alfonso F. Torres-Rua, Mac McKee, William Kustas, Héctor Nieto, and Calvin Coopmans "Validation of digital surface models (DSMs) retrieved from unmanned aerial vehicle (UAV) point clouds using geometrical information from shadows", Proc. SPIE 11008, Autonomous Air and Ground Sensing Systems for Agricultural Optimization and Phenotyping IV, 110080L (14 May 2019); http://dx.doi.org/10.1117/12.2519694

This Conference Paper is brought to you for free and open access by the AggieAir at DigitalCommons@USU. It has been accepted for inclusion in AggieAir Publications by an authorized administrator of DigitalCommons@USU. For more information, please contact digitalcommons@usu.edu.

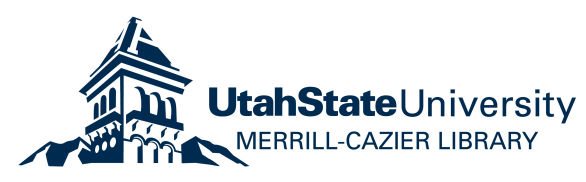




\section{Validation of digital surface models (DSMs) retrieved from unmanned aerial vehicle (UAV) point clouds using geometrical information from shadows}

Mahyar Aboutalebi, Alfonso F. Torres-Rua, Mac McKee, William Kustas, Héctor Nieto, et al.

Mahyar Aboutalebi, Alfonso F. Torres-Rua, Mac McKee, William Kustas, Héctor Nieto, Calvin Coopmans, "Validation of digital surface models (DSMs) retrieved from unmanned aerial vehicle (UAV) point clouds using geometrical information from shadows," Proc. SPIE 11008, Autonomous Air and Ground Sensing Systems for Agricultural Optimization and Phenotyping IV, 110080L (14 May 2019); doi: 10.1117/12.2519694

Event: SPIE Defense + Commercial Sensing, 2019, Baltimore, Maryland, United States 


\title{
Validation of digital surface models (DSMs) retrieved from unmanned aerial vehicle (UAV) point clouds using geometrical information from shadows
}

\author{
Mahyar Aboutalebi*a, Alfonso F. Torres-Rua ${ }^{\mathrm{a}}$, Mac McKee ${ }^{\mathrm{a}}$, William Kustas ${ }^{\mathrm{b}}$, Hector Nieto ${ }^{\mathrm{c}}$, \\ and Calvin Coopmans ${ }^{\mathrm{d}}$ \\ ${ }^{a}$ Utah Water Research Laboratory, Department of Civil and Environmental Engineering, Utah \\ State University, 8200 Old Main Hill, Logan, UT, USA. \\ ${ }^{b}$ U. S. Department of Agriculture, Agricultural Research Service, Hydrology and Remote \\ Sensing Laboratory,Beltsville, MD, USA. \\ ${ }^{\mathrm{c}}$ COMPLUTIG, Complutum Tecnologas de la Informacin Geogrfica.S.L, Madrid, Spain. \\ dElectrical Engineering Department, Utah State University, 8200 Old Main Hill, Logan, UT, \\ USA.
}

\begin{abstract}
Theoretically, the appearance of shadows in aerial imagery is not desirable for researchers because it leads to errors in object classification and bias in the calculation of indices. In contrast, shadows contain useful geometrical information about the objects blocking the light. Several studies have focused on estimation of building heights in urban areas using the length of shadows. This type of information can be used to predict the population of a region, water demand, etc., in urban areas. With the emergence of unmanned aerial vehicles (UAVs) and the availability of high- to super-high-resolution imagery, the important questions relating to shadows have received more attention. Three-dimensional imagery generated using UAV-based photogrammetric techniques can be very useful, particularly in agricultural applications such as in the development of an empirical equation between biomass or yield and the geometrical information of canopies or crops. However, evaluating the accuracy of the canopy or crop height requires labor-intensive efforts. In contrast, the geometrical relationship between the length of the shadows and the crop or canopy height can be inversely solved using the shadow length measured. In this study, object heights retrieved from UAV point clouds are validated using the geometrical shadow information retrieved from three sets of high-resolution imagery captured by Utah State University's AggieAir UAV system. These flights were conducted in 2014 and 2015 over a commercial vineyard located in California for the USDA Agricultural Research Service Grape Remote sensing Atmospheric Profile and Evapotranspiration Experiment (GRAPEX) Program. The results showed that, although this approach could be computationally expensive, it is faster than fieldwork and does not require an expensive and accurate instrument such as a real-time kinematic (RTK) GPS.
\end{abstract}

Keywords: Shadow, Point clouds, LIDAR, Vegetation Indices, GRAPEX, AggieAir, UAS, UAV

\section{INTRODUCTION}

Shadows are inevitable features in aerial imagery, and in most cases they are considered as a separate class, leading to errors in image processing and analysis procedures. For instance, because of the similarities in the spectral properties of shadows and water, particularly in the visible bands, most shadow detection methods fail to separate these two classes from one another (Garousi-Nejad et al. 20191). Chen et al. $(2007)^{2}$ showed that objects with an inherently low reflectance, such as water bodies, were mistaken for shaded areas when they were using machine learning algorithms to detect shadows. Results from the work of Aboutalebi et al. $\left(2018 \mathrm{a},{ }^{3} \mathrm{~b},{ }^{4}\right.$ and $\left.2019^{5}\right)$ on shadow detection and compensation techniques indicated that shadows can have a

Further author information: (Send correspondence to Mahyar Aboutalebi)

Mahyar Aboutalebi: E-mail: Mahyar.Aboutalebi@gmail.com

Autonomous Air and Ground Sensing Systems for Agricultural Optimization and Phenotyping IV edited by J. Alex Thomasson, Mac McKee, Robert J. Moorhead, Proc. of SPIE Vol. 11008,

110080L · @ 2019 SPIE · CCC code: 0277-786X/19/\$18 - doi: 10.1117/12.2519694 
significant impact on calculation of VIs and energy balance components, while shadow compensation methods were not able to completely recover inter-rows and canopy VIs with rapidly changing slope and elevation. They found that recovering shadow information using a shadow compensation method can improve the performance of evapotranspiration (ET) remote sensing models.

Although shadows can lead to a bias in VIs and decrease the accuracy of classification methods, they are recognized as a valuable source of information to estimate the geometrical information of an object blocking a light source. However, when using shadows for geometrical information estimates, the primary assumptions are that the object blocking the light is vertical and the shadows fall on a level ground (Irvin and Mckeown, 19896).

The use of shadows in aerial imagery to exploit the relationship between the geometrical information of an object and the cast shadows has a long history. Applying shadow information in an urban area, Cheng and Thiel $\left(1995^{7}\right)$ tried to estimate 42 building heights from shadows using a panchromatic band of a SPOT-image. The results showed an accuracy of $3.69 \mathrm{~m}$ for the proposed model in terms of root-mean-square error (RMSE). Lee and Kim $\left(2013^{8}\right)$ presented a new approach to automatic extraction of building heights in a urban area using IKONOS, KOMPSAT-2, QuickBIRD and Worldview-1 images and the volumetric shadow analysis (VSA) presented by Lee and $\operatorname{Kim}\left(2005^{9}\right)$. One advantage of VSA is that this method is not limited to situations in which the object must be vertical. Liasis and Stavrou $\left(2016^{10}\right)$ proposed a novel model to delineate building shadows for estimating building heights using Google Earth satellite images. In addition to estimating building heights, shadows information have been used to detect damage to buildings after disasters such as earthquakes (Mitomi et al. 2002 ${ }^{11}$ ). However, estimating building damage for mid-story collapses using shadows from highresolution imagery is questionable because the images are mostly acquired at nadir, showing only upper building surfaces and leaving other types of damages invisible (Iwasaki et al. 2012 ${ }^{12}$ ).

Ozdemir $\left(2008^{13}\right)$ used shadows in an environmental science application when they evaluated the relationship between stem volume by tree crown area and tree shadow area. Results showed a strong relationship between satellite-based shadow area and field-measured stem volume. Moreno et al. (2008 ${ }^{14}$ and $2010^{15}$ ), introduced a low-cost and convenient method to estimate soil surface roughness using shadow cast analysis under fixed sunlit situations.

In addition to the various applications using shadow information to estimate building heights and damages, cloud heights, soil roughness, and tree crown, other interesting topics benefit from shadows. For instance, Sandnes $\left(2011^{16}\right)$ estimated sun elevation using the relative lengths of objects and their shadows in an image collection to determine the geographical location of the photographer. Johansson et al. $\left(2009^{17}\right)$ presented a method to estimate vehicle size and position that combined a shadow detection and a shadow simulation model.

According to the literature reviews, the advent of UAVs and new satellites providing high- to super-highresolution imagery have made the impact of shadows and the information the can be extracted from shadows more pronounced. As discussed, shadows can be a valuable resource in various applications, particularly in urban areas. However, their application in precision agriculture is, as yet, an overlooked area. One application of shadows information in agricultural fields is the validation of digital surface and terrain models (DSM and DTM), specifically canopy height, retrieved from UAV point clouds. DSM and DTM are valuable sources of information that can be used for biomass parameters such as LAI, which is a key input for ET remote sensing models (Aboutalebi et al. 2018c ${ }^{18}$ ). For instance, an ET model called the two-source energy balance model (TSEB) requires canopy height, canopy width, and LAI to estimate energy fluxes. Since estimation of canopy height and canopy width at the spatial scale without 3D imagery is difficult, usually these two parameters are modeled with LAI using empirical curve fitting (Nieto et al. $2018^{19}$ ). However, with the availability of point clouds or LIDAR datasets, they can be directly derived from high-resolution imagery at the spatial scale.

In this study, three sets of AggieAir UAV imagery captured in 2014, and 2015 are used to validate object heights estimated by the AggieAir UAV point clouds. The case study was at a commercial vineyard located in California in conjunction with the USDA Agricultural Research Service Grape Remote sensing Atmospheric Profile and Evapotranspiration Experiment (GRAPEX) Program. The canopy heights are retrieved by subtracting NASA Goddard's LiDAR datasets (DTM) from UAV point clouds (DSM). Next, the canopy heights are validated using the geometrical shadow information retrieved from the shadow layers of three sets of high-resolution imagery. 


\section{MATERIALS AND METHODS}

\subsection{Area of Study and UAV Sensor Description}

For the current study, three high-resolution images (finer than $20 \mathrm{~cm}$ ) were captured by a small UAV in August 2014 and in June and July 2015 over a Pinot Noir vineyard located near Lodi, California (38.29 N 121.12 W), in Sacramento County as part of the GRAPEX project. These UAV flights were synchronized with Landsat satellite overpass dates and times. The UAV was operated by the AggieAir UAV Research Group at the Utah Water Research Laboratory at Utah State University.

In the study area, the training system in the vineyard was "U" shaped trellises and canes trained upwards. The vine trellises were $3.35 \mathrm{~m}$ apart, and the height to first and second cordon was about 1.45 and $1.9 \mathrm{~m}$, respectively (Kustas et al. $2018^{20}$ ).

Figure 1 shows examples of images captured by the UAV and the NASA phenocam over the study area. Camera and optical filter information, fieldwork dates, vineyard phenological stages, and imagery resolution are summarized in Tables 1 and 2.

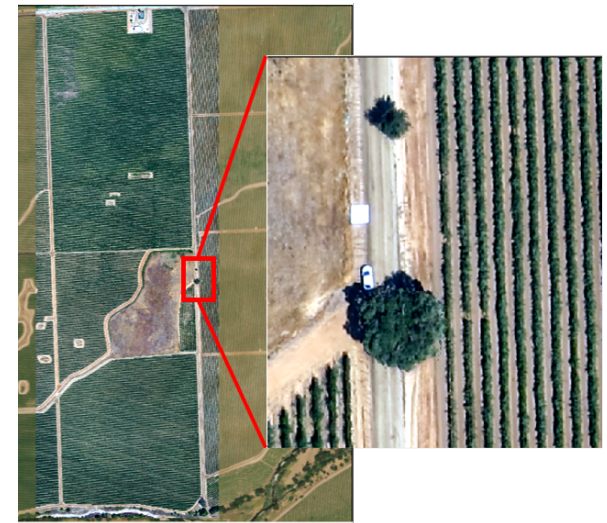

(a)

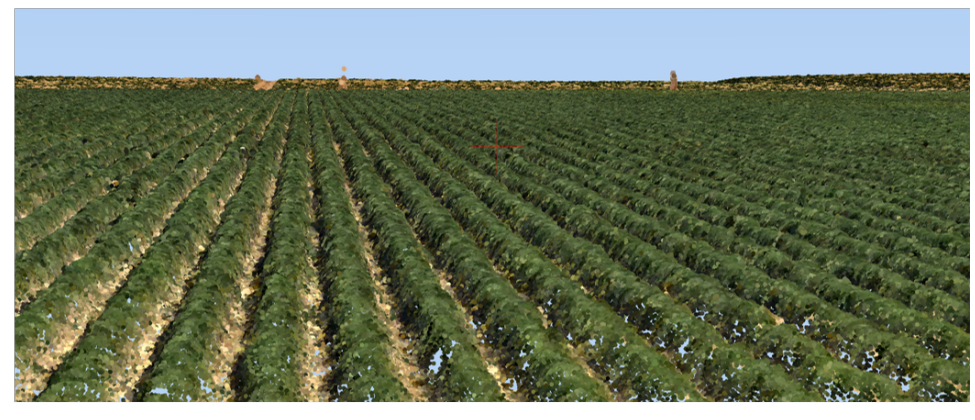

(b)

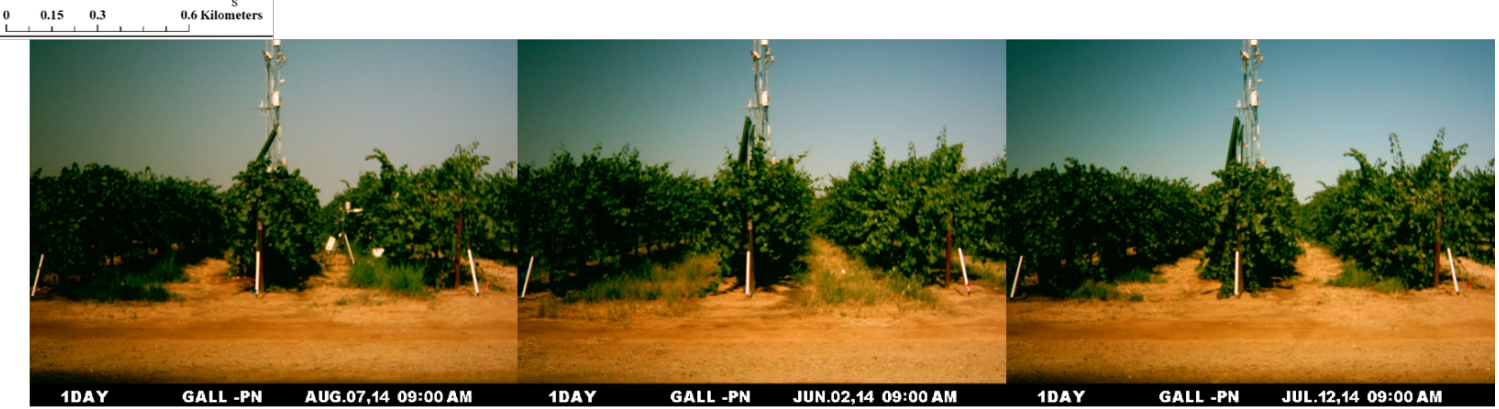

(c)

(d)

(e)

Figure 1. Example of an aerial image of the study area captured by the AggieAir UAV (a), point clouds (b) and NASA phenocam photographs for the same site captured at August (c), Jun (d), July (e).

Table 1. Dates, times, cameras and optical filters used to capture images with the UAV

\begin{tabular}{|c|c|c|c|c|c|}
\hline \multirow{2}{*}{ Date } & \multicolumn{2}{|c|}{ UAV Flight Time (PDT) } & \multirow{2}{*}{$\begin{array}{l}\text { UAV elevation } \\
\text { (agl) meters }\end{array}$} & \multicolumn{2}{|c|}{ Bands } \\
\hline & Launch Time & Landing Time & & RGB & NIR \\
\hline 20140809 & 11:30 AM & 11:50 AM & 450 & Cannon S95 & $\begin{array}{c}\text { Cannon S95 } \\
\text { modified }\end{array}$ \\
\hline 20150602 & 11:21 AM & 12:06 PM & 450 & $\begin{array}{l}\text { Lumenera } \\
\text { Lt65R Color }\end{array}$ & $\begin{array}{c}\text { Lumenera Lt65R } \\
\text { Monochrome }\end{array}$ \\
\hline 20150711 & 11:26 AM & 12:00 PM & 450 & $\begin{array}{c}\text { Lumenera } \\
\text { Lt65R Color }\end{array}$ & $\begin{array}{c}\text { Lumenera Lt65R } \\
\text { Monochrome }\end{array}$ \\
\hline
\end{tabular}


Table 2. Dates, optical, DSM and thermal resolution, point cloud density and phenological stages of the vineyard when the images were captured by the UAV

\begin{tabular}{|c|c|c|c|c|}
\hline Date & $\begin{array}{c}\text { Optical and } \\
\text { DSM resolution }\end{array}$ & $\begin{array}{c}\text { Thermal } \\
\text { resolution }\end{array}$ & $\begin{array}{c}\text { Point cloud density } \\
\left(\text { point } / \mathrm{m}^{\wedge} 2\right)\end{array}$ & Phenological stage \\
\hline 20140809 & $15 \mathrm{~cm}$ & $60 \mathrm{~cm}$ & 37 & near harvest \\
\hline 20150602 & $10 \mathrm{~cm}$ & $60 \mathrm{~cm}$ & 118 & near veraison \\
\hline 20150711 & $10 \mathrm{~cm}$ & $60 \mathrm{~cm}$ & 108 & veraison to harvest \\
\hline
\end{tabular}

As described in Tables 1 and 2, the imagery covers all three major phenological vineyard stages. Cameras used in the current study ranged from consumer-grade Canon S95 cameras to industrial type Lumenera monochrome cameras fitted with narrowband filters equivalent to Landsat 8 specifications. The thermal resolution for all four flights was $60 \mathrm{~cm}$ and the visible and near-infrared (VNIR) spatial resolutions were $10 \mathrm{~cm}$ except for the August flight.

Imagery acquisition was followed by a two-step image processing phase, including (1) radiometric calibration and (2) image mosaicking and orthorectification. In this study, a method developed by Neale and Crowther, $1994^{21}$ and Crowther, $1992^{22}$ ) is used for the radiometric calibration. This method was designed based on the reference panel readings. In the image mosaicking and orthorectification step, all image frames were merged into one mosaic and image rectified using Agisoft Photoscan software ${ }^{23}$ and control point coordinate s were measured by an Real-Time Kinematic (RTK) GPS instrument. The output of this step is an orthorectified reflectance mosaic (Elarab et al. $2015^{24}$ ). In addition to the orthorectified reflectance mosaic image, point clouds are provided by AgiSoft as a separate file in the .las format.

\subsection{Methodology}

The methodology of this study is shown in Fig 2. The steps of the methodology are (1) create sample points, (2) detect shadows using an index-based method as an observed dataset, measure shadow lengths, calculate actual heights, (3) extract point clouds and LIDAR ground values for sample points and calculate estimated heights, and (4) compare actual heights (based on shadow lengths) with estimated heights (DSM-DTM). 


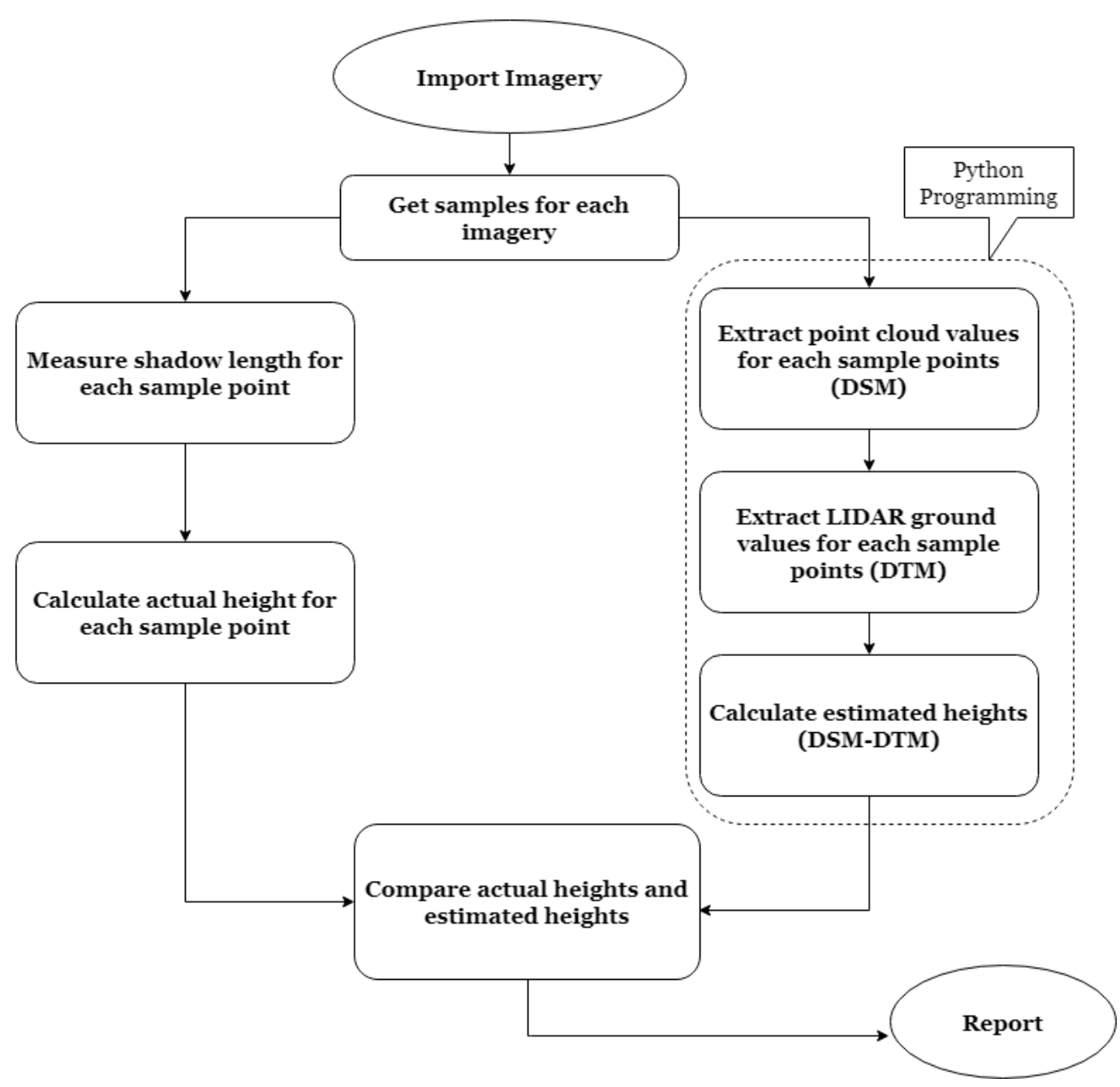

Figure 2. A flowchart illustrating the process of the study

As shown in Fig 2, 50 sample points are selected and marked as the first step. In step 2, shaded pixels for those 50 sample grids are detected using an index-based shadow detection method. Aboutalebi et al. 2018b evaluated four different shadow detection methods for this study area and found that the index-based method is able to detect shaded pixel better than the supervised, unsupervised, and physical-based methods. Thus, the shadow layer created by the index-based method is considered as the observed dataset. In step 3, the shadow lengths for each of the 50 sample points are measured. With shadow length and sun elevation, the actual height can be calculated simply using Eq. (1).

$$
H=\frac{L_{\text {shadow }}}{\sqrt{\frac{1}{\tan ^{2} \lambda^{\prime}}+\frac{1}{\tan ^{2} \lambda}-\frac{2 \cos \left(a-a^{\prime}\right)}{\tan ^{2} \lambda^{\prime} \times \tan ^{2} \lambda}}},
$$

in which, $H, L_{\text {shadows }}, \lambda, \lambda^{\prime}, a$, and $a^{\prime}$ are object height, shadow lengths, satellite (UAV) elevation, sun elevation, sun azimuth, and satellite (UAV) elevation, respectively. These parameters are graphically depicted in Fig 3.

Since AggieAir imagery is captured at nadir, $\tan ^{2} \lambda$ is infinity and Eq 1 is simplified to Eq. (2):

$$
H=\frac{L_{\text {shadow }}}{\sqrt{\frac{1}{\tan ^{2} \lambda^{\prime}}}},
$$




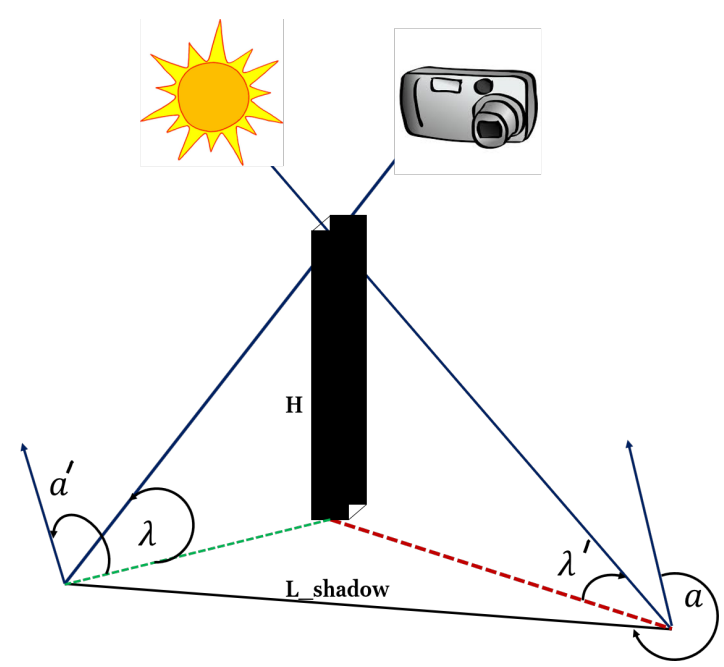

Figure 3. A graphical visualization for Eq. (1)

and $L_{\text {shadow }}$ is equal to Eq. (3):

$$
L_{\text {shadow }}=\frac{H}{\tan \lambda^{\prime}}
$$

In Eq. (2) and (3), sun elevation for each image can be calculated using geographical information (latitude and longitude) and flight time.

For extracting the object heights from point clouds, DSM and DTM values are extracted from point clouds and NASA LIDAR datasets using a Python script. DSM is produced based on point clouds, and DTM and LiDAR datasets are collected by the NASA G-LiHT project ${ }^{25}$ in 2013. Therefore, object heights can be estimated by subtracting DTM from DSM. Ultimately, the actual heights from shadow lengths and the estimated object heights from DSM and DTM are used to validate the accuracy of the point clouds. The error in the point cloud heights is equal to Eq. 4, which is visualized in Fig 4:

$$
H_{\text {actual }}-H_{\text {estimated }}=\left(L_{\text {shdaows }} \times \tan \lambda^{\prime}\right)-(D S M-D T M) .
$$



Figure 4. A graphical visualization for Eq. 4 
As mentioned in the introduction, this methodology is designed for vertical objects and shadows falling on a level ground (Irvin and Mckewon, 1989 ${ }^{6}$. The methodology has no limitations for poles, cars, and buildings, but it must be revised for trees and canopies due to their geometrical structure. For these two objects, we used a physical-based shadow mapping approach devised in ArcGIS that works with DSM and DTM. Then the lengths of the actual shadows and modeled shadows are converted to two heights for comparison: actual heights and virtual estimated heights. Therefore, the estimated heights for canopy and trees are their virtual estimated heights achieved from physical-based approach because they are not vertical objects (Fig 5).

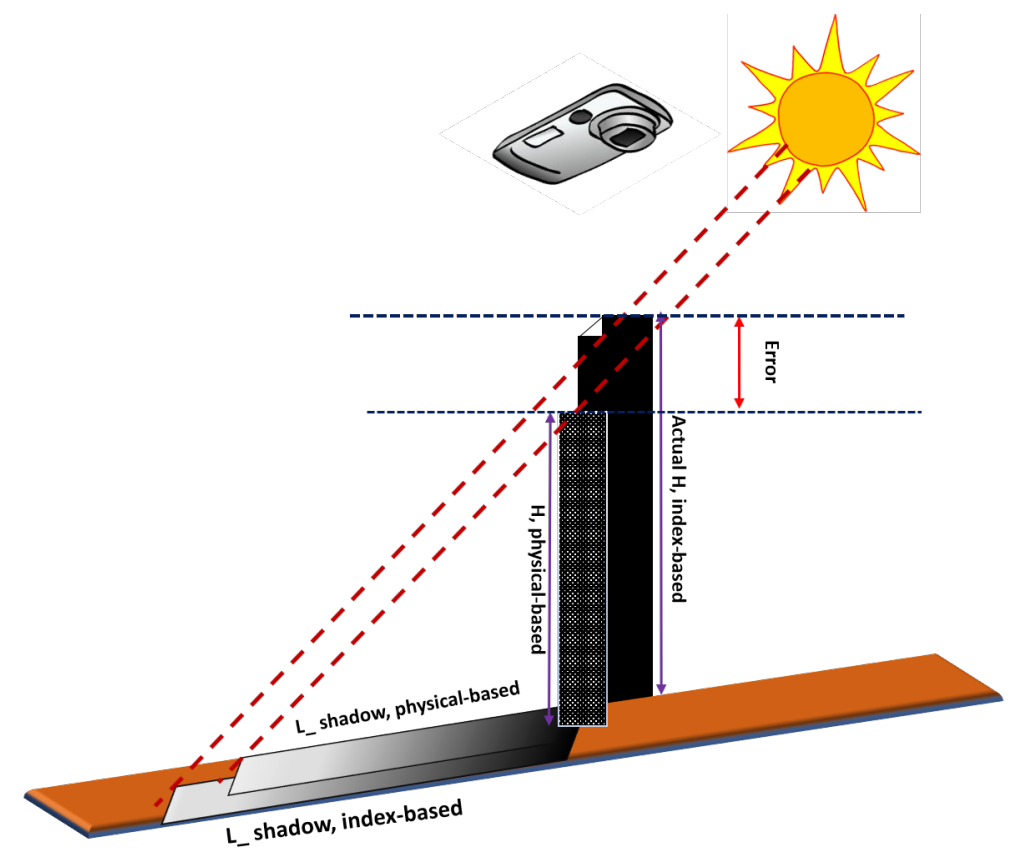

Figure 5. A graphical visualization for virtual estimated heights

\section{RESULTS AND DISCUSSION}

In this section, some sample points are shown, along with their actual heights (derived from shadow length) and estimated heights (from point clouds and ground LIDAR dataset). Next, the histograms analysis of errors (differences between actual and estimated heights) are illustrated. Ultimately, scatter plots are used to show the agreement between actual an estimated heights.

\subsection{Some Sample Points Along with their Actual and Estimated Heights}

As discussed in the study area section, for each flight, fifty sample points are considered to check and to validate the heights estimated from the point clouds. Knowing the sun elevation and shadow length allowed us to calculate the actual heights of sample points (Eq. 2). In this study, ArcGIS software's "Measure Distance" tool is used to measure the shadow lengths 3 times for each sample point. Sun elevation $\left(\lambda^{\prime}\right)$ is estimated using date, flight time, and geographical location information (latitude and longitude) for each flight (Ref. ${ }^{26}$ ). For instance, the average solar elevation for the first flight (Date: 09 August 2014, Time: 11:45 am, Latitude: 38.284484 , Longitude: $-121.121192)$ is $60.7^{\circ}$. Therefore, the coefficient $\left(\tan \lambda^{\prime}\right)$ for converting shadow length to actual height is 1.782 $\left(\right.$ Actual $_{\text {Height }}=1.782 \times$ Shadow $\left._{\text {Length }}\right)$. Fig 6 shows some of these sample points along with actual and estimated heights for different objects in the field (buildings, canopies, cars, poles, etc.) 

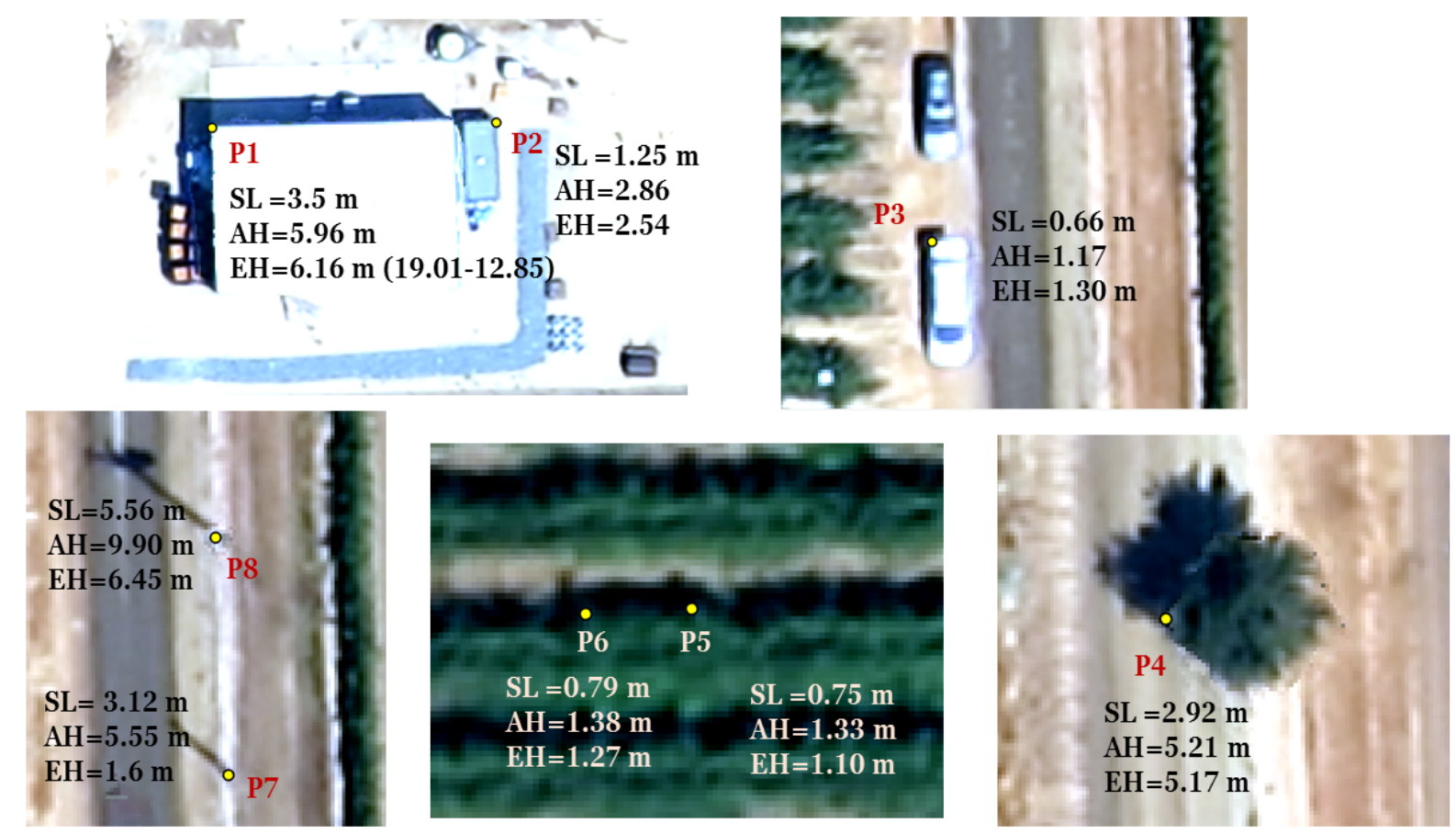

Figure 6. Sample points of different objects along with their shadow lengths (SL), actual heights (AH) and estimated heights $(\mathrm{EH})$

Fig 6 shows actual and estimated heights of 8 samples points from various objects such as building, canopy, tree, car, and pole. The sun elevations were $60.7^{\circ}, 66.9^{\circ}$, and $65.6^{\circ}$ for the August 2014 , June 2015 , and July 2015 flights, respectively. The shadow length is the average of three measurements using the "Measure Distance" tools in ArcGIS software. In Fig 6, the differences between actual height and estimated height are not larger than $20 \mathrm{~cm}$ except for poles. The height absolute errors in poles is up to $4 \mathrm{~m}$. It seems that point cloud estimation is not reliable for objects in which the surface area is small (e.g., poles). Based on our visual inspection, the height values for utility poles are close to the ground bare soil, which means that utility poles are not detected in the point cloud data sets (very low density point cloud). In contrast, for objects with high point cloud density, the point cloud performance is acceptable. Another observation is related to the underestimation of estimated heights derived from point clouds compared to actual heights. Although we cannot make a solid decision based on 8 points, the actual heights of most of the sample points showed higher values compared to estimated heights. This hypothesis will be evaluated by showing the histograms and scatter plots based on all 150 sample points for these three flights.

\subsection{Histogram Analysis of Error}

The histogram analysis of absolute error between actual heights and estimated heights for different objects is shown in Fig 7. 


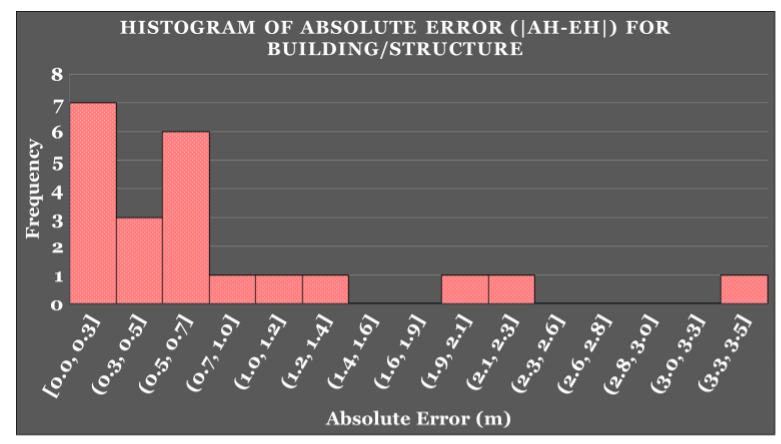

(a)

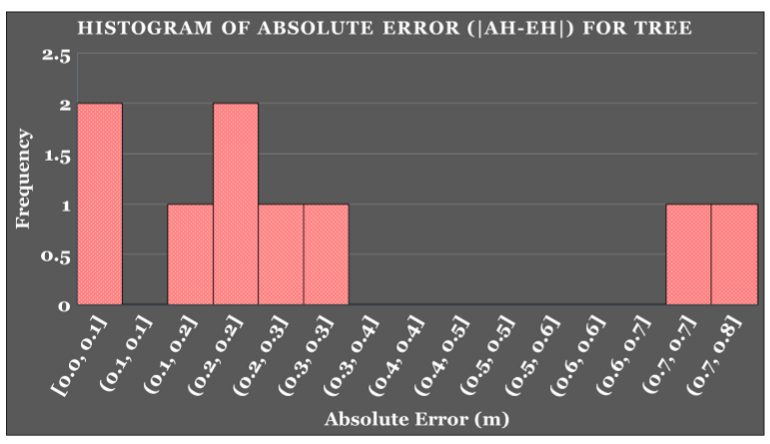

(c)

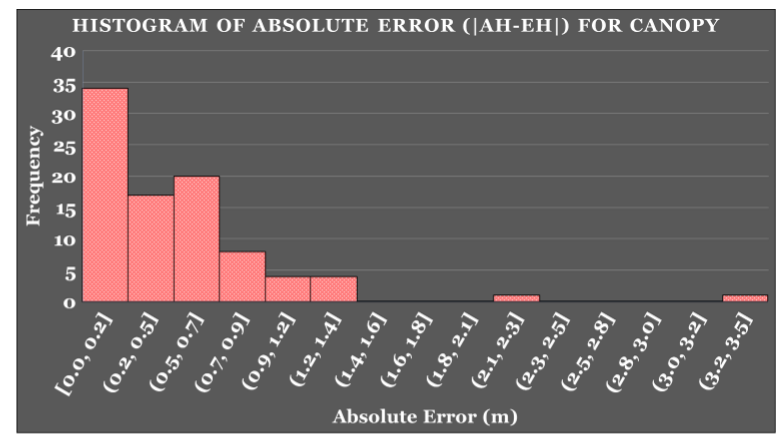

(b)

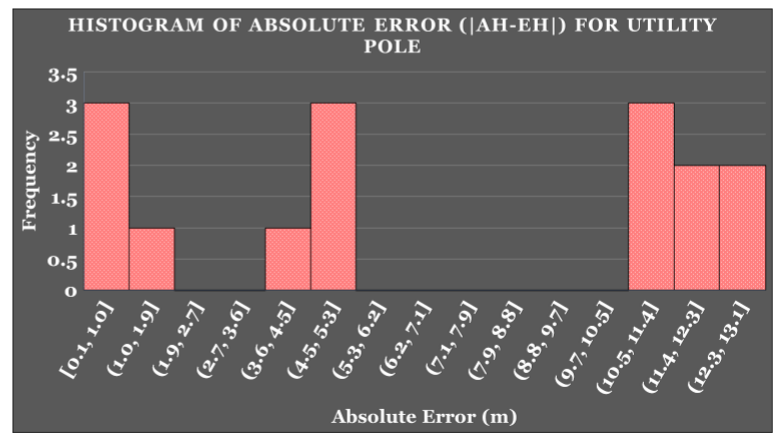

(d)

Figure 7. Histogram of absolute error for each object class in the imagery, $|A H-E H|$

Fig 7 shows that the height frequency absolute error for a building or structure is about $15 \mathrm{~cm}$. Considering building/structure heights of $\sim 3.5 \mathrm{~m}$, this amount of error represents less than $5 \%$ of those heights. However, the average absolute error for this class is $\sim 40 \mathrm{~cm}$, which is $\sim 12 \%$ of their average heights. Concerning the canopy class, the mean absolute error is about $35 \mathrm{~cm}$, which is more $20 \%$ of the average canopy heights $(1.6 \mathrm{~m})$, although the most frequent absolute error occurred at $10 \mathrm{~cm}$. For trees and poles, the histogram of absolute error is close to the uniform distribution ranging from $10-80 \mathrm{~cm}$ and $10 \mathrm{~cm}-13 \mathrm{~m}$ for trees and poles, respectively. The uniform distribution could be related to the low numbers of samples in these classes. However, the histogram analysis shows $20 \mathrm{~cm}$ error on average for trees, while their average heights is $7 \mathrm{~m}$ (less than $5 \%$ ). For poles, the high amount of errors more than $3 \mathrm{~m}$ are related to poles with no point cloud information on their surface. Removing those sample points, the average absolute error for poles is less than $1 \mathrm{~m}$ compared to average pole heights, which is $12 \mathrm{~m}$ (less than $7 \%$ error). Therefore, it can be concluded that, with increasing object heights, the error in point cloud decreases (from 20\% to 5\%). It should be noted that the car class is removed from analysis due to the movement of cars during flights (Fig 8). 


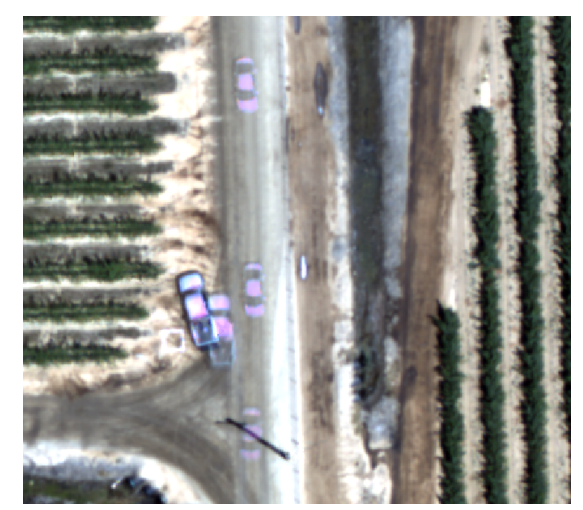

Figure 8. Example of moving cars during a flight time

\subsection{Scatter Plots of Estimated Heights and Actual Heights}

Fig 9 is illustrated to evaluate the agreement between actual heights calculated from shadow lengths and estimated heights using DSM and DTM. Fig 9 verifies the hypothesis of point cloud underestimation compared to actual height. In most cases, the actual heights are higher than the estimated ones. Removing the poles that are not detected in point clouds results in a strong agreement and relationship between actual and estimated heights. However, in the canopy class, many points have actual heights of twice the estimated ones. The density of these points decreases with decreasing canopy heights. This observation reinforces the idea that the error in point clouds increases with decreasing object heights. However, more higher resolution imagery from the current case study is needed to evaluate this observation.

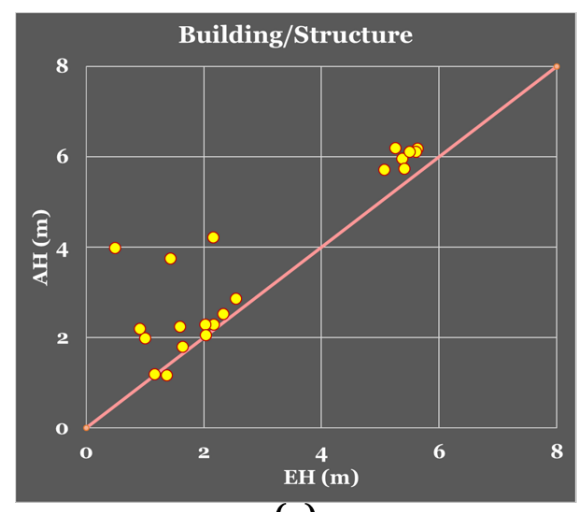

(a)

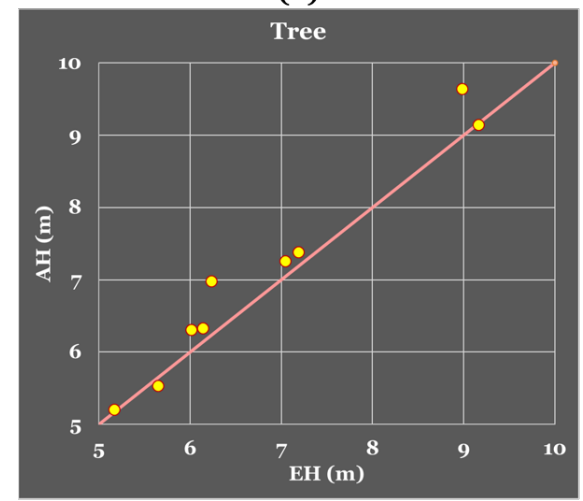

(c)



(b)

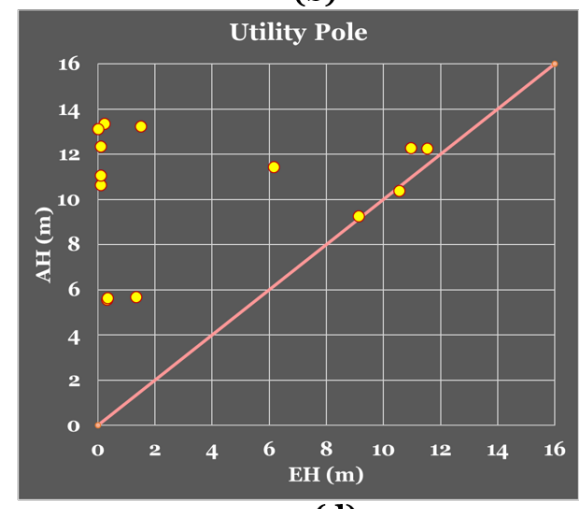

(d)

Figure 9. Sample points of different objects along with their shadow length (SL), actual heights (AH) and estimated heights $(\mathrm{EH})$ 


\section{CONCLUSION}

In this study, an approach to validate the UAV point clouds product was presented. A commercial vineyard located in California was considered as the study of area, and three sets of high-resolution imagery captured by AggieAir UAV and one ground LIDAR dataset were used to compare the actual object heights calculated from shadow lengths and estimated heights from DSM and DTM. 150 samples points along with their shadow lengths, DSM and DTM values were selected for this comparison. In summary, results indicated that (1) point clouds underestimated object heights, (2) with decreasing object heights, the absolute error increases, (3) the average of absolute error for trees, buildings and poles was less than $7 \%$ of their heights, while it was $20 \%$ of canopy heights. Although validation of point clouds using shadow length can be time-consuming, it is still faster than fieldwork, does not require expensive and precise instruments, and can be used for regions that don't have in-situ height measurements.

\section{ACKNOWLEDGMENTS}

The authors would like to thank Carri Richards for editing the manuscript and the Utah Water Research Laboratory for financially support of this project.

\section{REFERENCES}

[1] Garousi-Nejad, I., Tarboton, D., Aboutalebi, M., and Torres-Rua, A., "Terrain analysis enhancements to the height above nearest drainage flood inundation mapping method," Water Resources Research. In press (2019).

[2] Chen, Y., Wen, D., Jing, L., and Shi, P., "Shadow information recovery in urban areas from very high resolution satellite imagery", International Journal of Remote Sensing. 28(15), 3249-3254 (2007).

[3] Aboutalebi, M., Torres-Rua, A., McKee, M., Kustas, W.P., Nieto, H., and Coopmans, C., "Behavior of vegetation/soil indices in shaded and sunlit pixels and evaluation of different shadow compensation methods using UAV high-resolution imagery over vineyards," Proc. SPIE 10664, Autonomous Air and Ground Sensing Systems for Agricultural Optimization and Phenotyping III, 1066407 (2018).

[4] Aboutalebi, M., Torres-Rua, A., Kustas, W.P., Nieto, H., Coopmans, C., and McKee, M., "Assessment of different methods for shadow detection in high-resolution optical imagery and evaluation of shadow impact on calculation of NDVI, and evapotranspiration," Irrigation science. 1-23 (2018). DOI: 10.1007/s00271-0180613-9.

[5] Aboutalebi, M., Torres-Rua, A., McKee, M., Nieto, H., Kustas, W.P., Coopmans, C., "The impact of shadows on partitioning of radiometric temperature to canopy and soil temperature based on the contextual two-source energy balance model (TSEB-2T)," Proc. SPIE 11008, Autonomous Air and Ground Sensing Systems for Agricultural Optimization and Phenotyping III, 1100819 (2019).

[6] Irvin, R., and Mckeown, D., "Methods for exploiting the relationship between buildings and their shadows in aerial imagery," IEEE Transactions on Systems, Man, and Cybernetics. 19(6), 1564-1575 (1989).

[7] Cheng, F., and Thiel, K., "Delimiting the building heights in a city from the shadow in a panchromatic image-Part 1: test of 42 buildings," International Journal of Remote Sensing. 16, 409-415 (1995).

[8] Lee, T., and Kim, T., "Automatic building height extraction by volumetric shadow analysis of monoscopic imagery," International Journal of Remote Sensing. 34(16), 5834-5850 (2013). DOI: 10.1080/01431161.2013.796434.

[9] Lee, T., and T. Kim., "Reconstruction of 3D building structures from IKONOS images through monoscopic line and shadow analysis," Processing of Asian Conference on Remote Sensing. Hanoi, November 711 (2005).

[10] Liasis, G., and Stavrou, S., "Satellite images analysis for shadow detection and building height estimation," ISPRS Journal of Photogrammetry and Remote Sensing. 119, 437-150 (2016).

[11] Mitomi, H., Matsuoka, M., Yamazaki, F., Taniguchi, H., and Ogawa, Y., "Determination of the areas with building damage due to the 1995 Kobe earthquake using airborne MSS images," Proceedings of the IEEE 2002 International Geoscience and Remote Sensing Symposium. 2871-2873 (2002). 
[12] Iwasaki, Y., Wen, L., and Yamazaki, F., "Detection of building height and collapse model from the measuremnt of shadow length in optical images and layover in SAR intensity images," Journal of Japan Association for Earthquake Engineering. 12(6), 133-146 (2012).

[13] Ozdemir, I., "Estimating stem volume by tree crown area and tree shadow area extracted from pansharpened Quickbird imagery in open Crimean juniper forests," International Journal of Remote Sensing. 29(19), 56435655 (2008).

[14] Moreno, R.G., Requejo, A.S., Tarquis, A. M., Barrington, S., and Diaz Alvarez, M. C., "A shadow analysis method to measure soil surface roughness," Geoderma, 146, 201-208, (2008).

[15] Moreno, R.G., Daz Alvarez. M.C., Tarquis, A.M., Gonzlez, A., and Saa, R.A., "Shadow analysis of soil surface roughness compared to the chainset method and direct measurement of micro-relief," Biogeosciences. 7, 2477-87 (2010). DOI:10.5194/bg-7-2477-2010.

[16] Sandnes, F.E., "Determining the geographical location of image scenes based on object shadow lengths," Journal of Signal Processing Systems. 65, 35-47 (2011).

[17] Johansson, B., Wiklund, J., Forssn, P. and Granlund, G., "Combining shadow detection and simulation for estimation of vehicle size and position, Pattern Recognition Letter. 30(8), 751-759 (2009).

[18] Aboutalebi, M., Torres-Rua, A., and Allen, N., "Multispectral remote sensing for yield estimation using high-resolution imagery from an unmanned aerial vehicle", Proc. SPIE 10664, Autonomous Air and Ground Sensing Systems for Agricultural Optimization and Phenotyping III, 106640K (2018). DOI: $10.1117 / 12.2305888$.

[19] Nieto, H., Kustas, W., Gao, F., Alfieri, J., Torres, A., and Hipps, L., "Impact of different within canopy wind attenuation formulations on modelling evapotranspiration using TSEB," Irrigation Science. 1-17 (2018). https://doi.org/10.1007/s00271-018-0611-y.

[20] Kustas, W.P., M.C. Anderson, J.G. Alfieri, K. Knipper, A. Torres-Rua, C.K. Parry, H. Nieto, N. Agam, W.A. White, F. Gao, L. McKee, J.H. Prueger, L.E. Hipps, S. Los, M.M. Alsina, L. Sanchez, B. Sams, N. Dokoozlian, M. McKee, S. Jones, Y. Yang, T.G. Wilson, F. Lei, A. McElrone, J.L. Heitman, A.M. Howard, K. Post, F. Melton, and C. Hain, "The grape remote sensing atmospheric profile and evapotranspiration experiment (GRAPEX)," Bulletin of the American Meteorological Society. 99, 1791-1812 (2018).

[21] Neale, C.M., and Crowther, B.G., "An airborne multispectral video/radiometer remote sensing system: development and calibration. Remote Sensing of Environment. 49(3) 187-194 (1994).

[22] Crowther, B.G. "Radiometric calibration of multispectral video imagery." Doctoral dissertation, Utah State University. Department of biological and Irrigation Engineering, (1992).

[23] AgiSoft, L. L. C., and Russia St Petersburg. "Agisoft photoscan," Professional Edition (2016).

[24] Elarab, M., Ticlavilca, A.M., Torres-Rua, A.F., Maslova, I., and McKee, M., "Estimating chlorophyll with thermal and broadband multispectral high resolution imagery from an unmanned aerial system using relevance vector machines for precision agriculture," International Journal of Applied Earth Observation and Geoinformation. 43, 32-42 (2015).

[25] Cook, B. D., L. W. Corp, R. F. Nelson, E. M. Middleton, D. C. Morton, J. T. McCorkel, J. G. Masek, K. J. Ranson, V. Ly, and P. M. Montesano, "NASA Goddard's Lidar, hyperspectral and thermal (G-LiHT) airborne imager," Remote Sensing. 5 4045-4066 (2013). DOI:10.3390/rs5084045.

[26] https://keisan.casio.com/exec/system/1224682277 